\title{
A Razón de Santo: Ultimos Lances de Fray Servando
}

\author{
“...que las razones del Santo \\ no concluyen su intento..." \\ Fray Servando, Memorias \\ " ¡Miserable hombre de mí! ¿Quién \\ me librará del cuerpo de esta muerte?" \\ San Pablo, Epistola a los Romanos, 7, XXIV.
}

En 1882 se exhiben cuatro momias en una feria de Bruselas. Se trata de un retablo que bajo el rótulo de Gran Panóptico de la Inquisición muestra al ojo belga cuatro vestigios de la crueldad católica. El fervor hagiográfico insiste en que una de las momias es la de fray Servando Teresa de Mier Noriega y Guerra, pero no designa a ninguna en particular pues, desde este extremo de la leyenda, los cuatro martirios disecados apenas servirían de umbral para una de las biografías más ricas de América. Según la evidencia momificada, fray Servando puede habernos legado la momia natural de una persona que sufrio el tormento de fuego, puestos los pies en un brasero, o la momia que sufrio el tormento del agua, o la que sufrio el martirio de la rueda, o la que tiene los nervios de la cara torcidos por la pena de la angustia. ${ }^{1}$ Por lo pronto, y siguiendo el ejemplo de Reynaldo Arenas en su novela $E l$ mundo alucinante, conviene dejar al fraile dentro del Gran Panoptico para que, tanto su figura como el gran ojo que la asedia desde todos los rincones, puedan multiplicarse en libertad aprisionada.

Aprisionada, pues la última cárcel de fray Servando es la de la mirada que envuelve o, como diría Guzmán de Alfarache, que engolfa los cuatro torcidos monumentos a su muerte; las cuatro burlas a los que todavía nos aferramos, del lado de la vida, a las reliquias, a los restos del vivir prisionero. Es a este deseo de fijeza al que Arenas opone la

\footnotetext{
1 El hagiógrafo de Eduardo de Ontañón concluye su pintoresca vida, Desasosiegos de fray Servando, conversando con el fantasma del fraile, luego de enumerar las momias y anadir: "Cualquiera que sea, [es decir, cualquiera de las momias] nuestro frailecico continúa sus peripecias, que acaso no han parado a la hora de ésta, y sigue enseñando-paisajes, gentes y cosas-los dientes desde cualquiera sabe qué rincón del mundo." Ver, Desasosiegos de fray Servando, (México: Ediciones Xochitl, 1948), p. 171.
} 
frase más lapidaria de las que inventa para el fraile: " "QQue suceda! iQue suceda siempre algo! Mi fe está siempre por encima de mis resultados." ${ }^{2}$ Es ésta su ancha locura, la que por no caber en ninguna de sus prisiones obliga a repasarlas todas.

Yo he optado por la del cuerpo, siendo en esto fiel, creo, a ciertas obsesiones generadas en el texto de El mundo alucinante. Es preciso aferrarse al cuerpo, ya que es desde él que en El mundo alucinante se salta y se gesticula hacia el término trascendente (sea éste Revolucion o Gran Noche Estrellada). Es la constancia de este nexo con lo trascendental, en el plano de la acción y de las ideas, lo que trataré de bosquejar.

La tradición es rica en ejemplos sobre el cuerpo-prision, sobre la sepultura portátil de Quevedo. La prisión corporal es para Ignacio de Loyola el punto de partida para sus ejercicios en busca de lo invisible. En el "Primer preludio," dice que "en la invisible, como es aquí de los pecados, la composición será ver con la vista imaginativa y considerar mi ánima ser encarcerada en este cuerpo corruptible, y todo el compósito en este valle, como desterrado, entre brutos animales. Digo todo el compósito de ánima y cuerpo.' 3 El alma, emparedada en su fortaleza-celda, sola con la mirada de Dios, es el núcleo invisible, incomunicado dentro del cuerpo, que es prisión o, en el mejor de los casos, colectividad de miembros en precaria armonia. Según San Pablo, en su epistola a los corintios (ver todo el I Corintios, 12), es necesario "que no haya desavenencia en el cuerpo, sino que los miembros todos se interesen los unos por los otros." Pero esta armonía y esta visibilidad son epidérmicas, ya que "el hombre mira a la cara, mas Dios ve dentro del corazón." La interioridad encarcelada se preserva así intacta para la comunicación beatifica: "Ahora vemos por espejo, en oscuridad; mas entonces veremos cara a cara. Ahora conozco en parte mas entonces conoceré como soy conocido"' (I Corintios, 13:XII).

Los Ejercicios espirituales constituyen una serie de actos solitarios, realizados en la cámara intrasubjetiva del ser que vive para Dios. Al final de El mundo alucinante, Arenas ha colocado a su fraile en situación análoga: en la estación de la calma. Y le ha hecho habitar un tiempo donde no existe la memoria, sino "sólo un presente despoblado. La revelación" (216). Es entonces que fray Servando creerá ir hacia Dios, pero sentirá miedo, "miedo de que al final de aquellos vastos recintos [no haya] nadie esperándolo. Miedo a quedarse flotando en un vacío infinito, girando por un tiempo despoblado, por una soledad inalterable donde ni siquiera existiría el consuelo de la fe. Miedo a quedar totalmente desengañado" (216). La interioridad enrarecida del fraile es entonces el alma transparente de dos cuerpos: el de la vasta osamenta del palacio presidencial, de la pajarera rectangular, llena de "millones de objetos inútiles," donde vive huesped de don Guadalupe Victoria, y ese otro cuerpo, el de la colectividad alucinada y orgiástica que adora a la imagen de la bella patrona, Guadalupe-Tonatzin, frente a la catedral, "cuajada de luminarias en su torre y de tenderos en sus bóvedas, convertida en un ascua de oro"' (217).

He dicho que la de fray Servando es alma de este abigarrado cuerpo, pero lo cierto es que, en El mundo alucinante, lo uno y lo otro (lo visible y lo invisible) no se comunican ni,

\footnotetext{
${ }^{2}$ Reynaldo Arenas, El mundo alucinante, (México: Editorial Diógenes, 1969), p. 60. Todas las citas provienen de esta edición.

${ }^{3}$ Monumenta Ignatiana; Series secunda, Exercitia spiritualia santi Ignatii de Loyola et eorum Directoria, (Madrid: 1919). Existe un sugerente ensayo sobre este aspecto del pensamiento de Ignacio de Loyola, escrito desde la perspectiva literaria, ver Walter J. Ong, "St. Ignatius' Prision-Cage and the Existentialist Situation," en The Barbarian Witbin and Otber Fugitive Essays, (New York: 1962) pp. 242-57.
} 
mucho menos, se funden en el hombre. No le es dado a éste alcanzar "la perfección de las constelaciones, su armonía inalterable," porque "seguramente existe algún desequilibrio"' (215). En efecto, entre el hombre y su proyecto, entre él y "el objetivo de toda civilización (de toda revolución, de toda lucha, de todo propósito)" se interpone su propio ser en desequilibrio, su condición de ser excedente, que le condena a inventarse destierros.

Se inscribe así Arenas en la tradición romántica, en su final o desdoble irónico. Daré ahora dos ejemplos de la literatura romántica en los que el añejo tema de la contienda del alma y el cuerpo se repite sobre el fondo de una doble trascendencia, propuesta más allá de la partida de los dioses. Contienda que se traduce en la siguiente doble interrogación: ¿Qué estructura terrestre podrá servir de cielo; donde se bará visible lo invisible?

A mbos ejemplos, tomados en relación, darán acceso al terreno donde lo político se manifestará según las antiguas visiones quiliásticas, utópicas y carnavalescas, dentro de un marco que habrá de denominarse barroco. Al rotular dicho complejo de actitudes empleando este vocablo no me interesa fijar ninguna relación, ya sea ésta histórica o formal. No se trata, ni tan siquiera, de usurpar o de adulterar un término de empleo disciplinario. Lo barroco actúa aquí como ese pasquín o cartel que precede, reduciéndolos a un nombre, los quehaceres del retablo. Pero, más allá de esta función prefatoria, lo barroco designaría aquí por lo menos una actitud hacia el cuerpo, que encuentro traída a su máximo punto de eclosión en este epigrama de Richard Crashaw sobre el Cristo lactante:

Suppose he had been tabled at thy Teats,

Thy hunger feels not what he eats:

He'll have his Teat ere long (a bloody one)

The Mother then must suck the Son

Importa extraer del interior de esta profusa selva de ambiguiedades, de perversas conflagraciones, (ya recorrida por Empson en Seven Types of Ambiguity) su grotesca energía, y el violento maridaje que consuma entre las dispersas partes de aquello que, por economía linguística, hubo de denominarse Cristo. Es la destrucción de esas previas economías doctrinales (estéticas, religiosas o políticas), es socavar sus fáciles vías unitivas, sustituyéndolas por una especie de dispersión reunida en cada uno de sus fugaces átomos, es el rigor ascético (y la sexualidad animal) manifiestos en lo que Empson llama "la monstruosa deidad hermafrodita;' es todo esto y aun más, lo que convoca aqui la señal de lo barroco. Lo barroco (asi entendido) sería entonces el índice de la crisis permanente de la modernidad girando en su umbral y, también, en el ámbito de su Representación Final. Se trata, en suma, del espectáculo que escinde el Final y el Principio, pero no como acontecimientos historiables, sino como repeticiones, siempre insuficientes, de un anhelo: el de desatar el libre juego de las criaturas.

En De la gramatología, Jacques Derrida ha destacado algunos pasajes del Emilio: "Ya no existimos donde estamos, sólo existimos donde no estamos," escribe Rousseau y pregunta, "¿Vale la pena tener un miedo tan grande a la muerte, con tal que aquello en que vivimos permanezca?', Claro que en lo barroco esta meditación se transforma en ${ }^{4}$ De la gramatologia, (Buenos Aires: Siglo XXI Editores, S. A., 1971), pp. 391-92. 
espectáculo, en el juego de máscaras tan aborrecido por Rousseau. Así todo, se puede leer en el Emilio una glosa inadvertida de la "presente sucesión de difuntos quevediana: "Librado de la inquietud de la esperanza, y seguro de perder así, poco a poco, la del deseo, viendo que el pasado ya no era nada para mí, intentaba ponerme por completo en el estado de un hombre que comienza a vivir. Me decía que, efectivamente, nunca hacíamos más que comenzar, y que no hay otra ligazón dentro de nuestra existencia que una sucesión de momentos presentes, el primero de los cuales siempre es el que está en acto. Nacemos y morimos a cada instante de nuestra vida." 5 El acto comunal, renovador, de la fiesta pública, lejos de degenerar en espectáculo donde se represente a través de las máscaras, deberá eliminar los obstáculos creados por la decadencia (los cuerpos rutilantes y emblemáticos) para lograr lo que Rousseau veía como la transparencia de los corazones. Que la Revolución de la que él es considerado profeta concluyese por entronizar la representación, nos lleva al segundo ejemplo, el de Victor Hugo.

Nuestra señora de Paris es obra del pueblo, en ella se conmemora su vivir orgánico, pre-moderno; época en que sus energías carnavalescas se traduciạn en imágenes que integraban al rostro del hombre, rostro sublime y grotesco, que se consumía a sí mismo y renacía cada año como espectáculo. Ciclo éste estacionario que será disuelto por la historia. Para el Hugo reaccionario, medievalista, la Revolución tuvo de aquelarre, fue Gran Sábado de Brujas. Su creencia en el mesmerismo, la armonía universaly el fluido vital, pertenece a la constelación ideológica que deslumbra a Esteban y que Victor Hugues rechaza en El siglo de las luces; cosmovisión unitiva y trascendental con que la revolución jacobina lucha como si lo hiciera con su propia sombra.

Quasimodo y Nuestra Señora ejemplifican la resolución arcaica de la perenne contienda (la del alma con el cuerpo) a nivel de lo que Gastón Bachelard ha llamado "los ensueños de la piedra habitada." "6 "'Seguramente existía," dice el narrador, "una especie de armonía misteriosa y pre-existente entre aquella criatura y aquel edificio. Cuando, pequeño todavía, se arrastraba tortuosamente y con sobresaltos bajo las tinieblas de sus bóvedas, parecía, con su rostro humano y sus miembros bestiales, el reptil natural de aquel enlosado, húmedo y sombrio, sobre el cual proyectaba tantas formas extrañas la sombra de los capiteles romanos...." $7 \mathrm{Y}$ en otro pasaje que equivale al responso de Hugo ante el cadáver cristiano:

Toda la iglesia tomaba una especie de aire fantástico, sobrenatural, horrible, abríanse aquí y allá ojos y bocas; oíanse ladrar a los perros, a las sierpes, a las tarascas de piedra que velan noche y día con el cuello tendido y la bocaza abierta, alrededor de la monstruosa catedral; y si se trataba de una noche de Navidad, en tanto que la campana gruesa que parecía jadear llamaba a los fieles a la misa ardiente de la media noche, extendiase un aire tal por la sombria fachada, que se diría que ésta devoraba a la muchedumbre y que el enorme rosetón la contemplaba. Y todo eso venía de Quasimodo. Egipto lo hubiese tomado por el dios de aquel templo, la Edad Media creíalo un demonio, en realidad era el alma de él.

5 De la gramatologia, pp. 391-92.

6 Ver todo el capitulo quinto de La poétique de l'espace, (Paris: PUF, 1958).

${ }^{7}$ Nuestra Señora de Parts, versión española de Amando Lázaro Ros, (Madrid: Aguilar, 1963), p. 346. 
Hasta tal punto era asi, que para aquellos que saben que Quasimodo ha existido, Nuestra Señora está hoy desierta, inanimada, muerta. Se tiene la sensación de que algo ha desaparecido. Aquel cuerpo inmenso está vacio, el espíritu lo ha abandonado, se ve el lugar y nada más. Es como un cráneo que conserva aún los agujeros para los ojos, pero sin mirada. ${ }^{8}$

Quasimodo es para Hugo la pura presencia, la negación de la máscara, pues supera a ésta en carne y hueso. Es rugosa momia que encarna en alma y segrega no la alegoría del hombre resucitado-como lo sería el caracol-sino la arquitectura osea de la Catedral, del cuerpo del que se ha fugado el alma, y de la tumba de la que se ha esfumado el cadáver. La consubstancialidad entre el monstruo de piedra y el de carne es un hecho arcaico, de cuando el hombre se veia incrustado en la memoria de sus dioses y estos le hablaban por la piedra. Rousseau rechaza la representación desde el sueño iluminado de la razón, mientras que Hugo concibe a Quasimodo, al anticristo que la encarna para anunciar su fin en los sacramentos callejeros del pueblo: en la plaza pública, como siempre, habrá hambre, hambre desnuda, huérfana, y la infatigable obrera-la misma que fray Servando burlará sobre las ondas del Atlántico de regreso a América-ya no tendrá casa.

La profusión arquitectónica en $E l$ mundo alucinante, sus palacios de estatuas que se derrumban, de jaulas que se suceden incrustadas unas a otras, sus entretejidos castillos y el entrecruce laberíntico de sus cadenas, son el emblema de cierta demencia edificadora enfrascada en tareas mortuorias, la misma que mueve a las ambiciosas marionetas que, según Michelet, remedan, en traje revolucionario, los gestos del Rey. Es la de Victor Hugues queriendo levantar un parque real en Cayena; "Venceré a la naturaleza de esta tierra," dice el edificador a Sofía, "levantaré estatuas y columnatas, trazaré caminos, abriré estanques de truchas, hasta donde alcanza la vista." 9 Por contraste, todos los contactos del fraile con la materia edificada son los del prisionero, cuyo cuerpo, remoto entre murallas y bajo cadenas, persiste en una sonrisa como "pájaro fantástico...tranquila, agitada por una especie de ternura imperdurable" (151). Entre los lugares visitados por el fraile hay dos que permiten fijar los dos extremos por los que se unen las tareas y las formas. Se trata en ambos casos de una soldadura utópica que el sueño de la Gran Revolución permite vislumbrar antes de que inaugure la dispersión que será su verdadera consecuencia.

No hay prioridad de ninguna clase entre dichos extremos. En uno, casi al final de la obra, fray Servando y José María Heredia visitan el paraíso. En el vasto jardín poblado por millones de aves, Heredia se transfigura en "un arbol formidable, cubierto de tórtolas, zarcetes, papagayos, búharos y lirones" (211), y él y fray Servando nadan desnudos y se fabrican trajes con hojas centellantes. El breve estado paradisiaco de la pareja ocupa una especie de tercer espacio o término, que es el favorito de El mundo alucinante. Hablo de una dimensión virtual, postulada como algo necesario y que se ubicaría entre las Memorias de fray Servando y la novela que Arenas se ha propuesto escribir. Algo que es el texto de $E l$ mundo alucinante en su estatuto refractario, diferencial, anunciado desde su primer y más célebre oración: "Venimos del corojal. No venimos del corojal. Yo y las dos Josefas venimos del corojal. Vengo solo del corojal." No me refiero a la socorrida sintesis sino, por el contrario, a las voces y gestos que la difieren y sirven de eco a la siguiente declaración

${ }^{8}$ Nuestra Senora de Parts, pp. 358-59.

${ }^{9}$ El sigh de las luces, (México: Compañáa General de Ediciones, 1966), p. 276. 
del umbral: "Lo más útil fue descubrir que tú y yo somos la misma persona" (9). Pues sí lo son, precisamente a través de todo lo que desvirtúa la ingenuidad de esta frase. Por ejemplo: "E1 fraile se acercó más al fraile y los dos sintieron una llama que casi los iba traspasando. El fraile retiró una mano. Y el fraile también la retiró. De manera que ambas manos quedaron en el mismo lugar. Horrible es el calor, dijeron las dos voces al mismo tiempo. Pero ya eran una'" (64). Se unen así el fraile que lo ha visto todo con el que no ha visto nada, el que va con el que viene, el que dice "iQue suceda! ¡Que suceda siempre algo!" con el que ya desea, por lo menos, ser momia. Pero se sabe, Arenas sabe, que para él-de este lado del trabajo "grandioso y grotesco del tiempo"- - ambos frailes serán uno, y él la sombra que los separe, que los rescate de su condición de desperdicios. En su paseo por los jardines del Rey de España, fray Servando, tras riesgoso tránsito por las tierras del amor, llega al país de los desperdicios, de la desolación, al país del tú contigo, al extremo opuesto a la visión paradisíaca.

En las tierras del amor carnal, la naturaleza y los pecados que la niegan según la vieja teología, se afirman por concentrada exageración, pero en la tierra de los buscadores es cuestión de probar que las formas no han nacido del mundo, pues el hombre niega su propia figura. A la demencia edificadora de los reyes y sus fantasmas se opone la inagotable energía de la no-naturaleza, la violencia reflexiva y masturbatoria de las obras que no terminan porque el trabajo que las persigue se entretiene en tratar de localizar las causas primeras y las finales. Nada de lo hecho y de lo configurado vale, pues la mirada que estos seres sienten reposar sobre sí (que no es otra que la de ellos mismos) exige que se le presenten evidencias, pruebas. En el juicio de la sinrazón la razón se juzga en cada una de sus sombras: "Y le pregunté a mi guía [cuenta el fraile] cuál era la búsqueda de aquel anciano, pues no daba siquiera la sensación de esperar nada. 'Tienes razón,' me respondió el muchacho, 'su aspecto no indica obstinación, y sin embargo es el más obstinado de todos los que has visto participar en esta cacería de cosas imposibles. Pretende lograr la eternidad"'(93). Y, más adelante, se detendrán frente a otro anciano que sostiene un espejo en la mano y con la otra se golpea el estómago pues, según el guía, quiere verse el alma. Fray Servando vuelve a ver al primer anciano antes de salir de aquel paraje: "Volvimos a ver al viejo empeñado en lograr la eternidad. Estaba ahora más inclinado que nunca, y el sol, que ya iba despuntándose sobre un costado del mundo, depositaba sus rayos sobre su cabeza lisa e inmóvil, con lo cual ésta resplandecía como otro sol más pequeño y fijo.... De todas las cosas que vi, esta cabeza despoblada, ya centellando, ya tocando la tierra, ya casi sucumbiendo, ha sido una de las que más recuerdo y la que me causa más tristeza. $Y$ es como si yo mismo me viera en esa posición: luchando inútilmente contra lo que ni siquiera se puede atacar" (94).

La prisión del tú-contigo, la más terrible, representa para fray Servando el punto absoluto del desengaño, de la vertiginosa fijeza que sus andanzas picarescas habrán de transformar en constante movimiento, pero sin dejar por ello de ser prisionero de lo que Melville llamó las ligaduras siamesas del bombre con sus semejantes.

Fray Servando dedicó su mejor párrafo a realzar este nexo: "Mi imaginación es un fuego, pero mi corazón está sobre la región de los truenos. No puedo aborrecer ni a mis enemigos. Porque de mis amigos, por supuesto, ninguno ha sufrido o fallecido sin el obsequio de mis lágrimas. Por no oprimir las hormiguillas suelo ir saltando en los caminos, 
y en las prisiones, de que cuento ocho años interpolados en veinticuatro de persecución, me he ocupado con cuidado de su subsistencia, estimando por muy grata en la soledad de los calabozos la compañía de estos pequeños seres vivientes." ${ }^{10}$ Es en este registro de su voz donde se oyen las voces de la paciencia milenaria, siempre en espera de la brecha que le permita salir y hacerse acto en $s u$ historia. La heterodoxia de fray Servando es tan antigua como los dogmas que combate pues, las esperanzas y energías que trata de aprovechar con fines políticos, son las del quialismo. Según él, la religión de los antiguos mexicanos fue "un cristianismo trastornado por el tiempo y la naturaleza equívoca de los geroglíficos." 11 Al destruir la nación azteca los españoles "destruían la misma religión que profesaban, $\mathrm{v}$ reponían las mismas imágenes, que quemaban porque estaban bajo diferentes símbolos.' 12 He aquí la variación del tu-contigo, del tu matándote a ti mismo que Arenas coloca en el espacio de la locura. Las labores del fraile destilan una verdad que él da en voz llana:

"Saben los pícaros que así como con pretexto de religión se subyugó a la América, así la Virgen de Guadalupe es el cabestro con que llevan los mexicanos a beber agua a la fuente del burro." '13

Hasta ahora, me he acercado a fray Servando a través de su cuerpo convertido en disecada reliquia, en juguete escondido detrás de cuatro gestos, de cuatro posibilidades, y que es de los que se miran pero no se tocan. De la soberanía fetichista de esta mirada, de esta ciencia panóptica que es emblema de la vida mirándose como disfraz de la muerte, me he remontado hasta el alma encarcerada de los Ejercicios espirituales, alma en oclusión para todo conducto que no sea el de la mirada de Dios. La exterioridad corpórea es ahora piedra, cárcel que guarda en su interior el reducto de las operaciones invisibles entre el ser y la divinidad. Las referencias a Rousseau y, sobre todo, a Nuestra Señora de París, trasladaron el nexo de lo corpóreo y lo intocable al plano de las colectividades; en ambos la plenitud de la Presencia implica una crítica del hombre según su potencial solidario. En Rousseau se trata del horizonte utópico de la transparencia de los corazones, y en Hugo de la memoria de una unión disuelta por el devenir de la historia, del recuerdo de aquel momento en que le fuera posible a la arcilla devolver el soplo que, en el origen, hizo de ella carne. Quasimodo anima la piedra, participa de su substancia. Al invocar estas visiones me he propuesto dramatizar un dato de suma importancia en cuanto a El mundo alucinante: los múltiples destellos que la errancia del fraile produce pueden ser organizados alrededor de una crítica de la utopía, siempre y cuando se tomen en cuenta una doble hipóstasis, la de la Historia, y la de su culminación orgánica, la Gran Revolución.

A primera vista, alejarse de "el rasgo deshumanizado que suponen las erudicciones adquiridas en los textos de historia"' (El mundo alucinante, p. 9), constituirá para Arenas el principio mismo de la libertad, el eficaz fermento del texto plural y refractario. Pero al quedar asi superada la historia no desaparece; no puede, en cuanto es el índice del trabajo, del sacrificio y de la renuncia que ocasionan el texto. Verla a través de esta reducción a los estatutos del hombre que labora mantiene vigente su posible vencimiento sobre el horizonte

\footnotetext{
10 Fray Servando Teresa de Mier, Memorias II, (México: Editorial Porrúa, 1946), p. 294. Todas las citas son de esta edición.

11 "Carta de despedida a los mexicanos escrita desde el castillo de San Juan de Ulua," incluida por Eduardo de Ontañón en Desasosiegos de fray Servando, pp. 182-96.

12 "Carta de despedida," pp. 191-92.

13 Memorias II, p. 197.
} 
de las tareas impuestas por la necesidad. La reducción marxista a que aludo, sin embargo, introduce la reificación de la naturaleza, convertida en mero objeto de la explotación por parte del hombre. La demencia edificadora a que he hecho referencia se inscribe en este cuadro enajenante. Pero si (de nuevo) "el objetivo de toda civilización (de toda revolución, de toda lucha, de todo propósito) [es] alcanzar la perfección de las constelaciones, su armonía inalterable" (215), cabe preguntarse si del hombre atado a sus labores no se pasará a otro, dominado por las entelequias, por la Gran Noche Estrellada; "la noche de las interrogaciones. La que enloqueció a Van Goth. La que había hecho dudar a Kant. La primera noche de David. La noche que habia desconcertado o iluminado a todos los hombres en todas las civilizaciones" (215). Esto sugiere la confluencia entre utopía y locura, en el seno de una dialéctica irresoluble.

Pues entre la congregación armónica de las estrellas (vasta escritura) y la procesión al santuario de Guadalupe, que habrá siempre de degenerar en orgía a ras de tierra, opera el desequilibrio del hombre y su secular desarraigo. Por su parte, fray Servando no puede dejar de incitar y de condenar esta propensidad quiliástica en el ser colectivo de sus semejantes. Condenar a la "chusma brutal que todo lo reduce a esquemas, gente que confunde la democracia con la mala educación"' (215), equivale a no trascender la situación del tú contigo, y a conferirle un sentido cósmico. La relación entre los astros y la utopía no es nueva; ya Tommaso Campanella creía que las siete protuberancias de su voluminoso cráneo representaban los siete planetas en conjunción talismánica con sus propósitos de dirigir la reforma mágico-religiosa del mundo. ${ }^{14}$ La utopia del Renacimiento es el cielo secularizado de la Edad Media, ha dicho Horkheimer, y añade algo que toda consideración de la utopía no puede ignorar si pretende rebasar el mero valor intencional del concepto: "La utopía ignora que el grado de desarrollo histórico, del que parte el impulso de su proyecto imaginario, constituye las condiciones materiales de su devenir, de su ser y de su perecer, e ignora que ha de conocerlas exactamente y en ellas ha de asentarse si pretende realizar algo.", 15

Ahora bien, la contemplación de la Gran Noche Estrellada le confirma al hombre el hecho de que vive en los tiempos del desgarramiento de la totalidad. A su vez, cierta crítica de la utopía la reduciría a las manifestaciones quiliásticas y utópico-totalitarias. Según esta tesis la revolución francesa sería la culminación de un conjunto de movimientos milenarios, irracionales, cuyos resultados modernos son bien sabidos. Pero limitar el impulso utópico a la dinámica de las antiguas locuras colectivas resulta tan infundado como lo es reducir dicho impulso al mero deseo o a la pura intencionalidad. En fin, en El mundo alucinante las aventuras de fray Servando y sus ideas sobre el pasado mexicano absolutizan la historia y su posible superación utópica. En cuanto a la historia, se la niega como el signo de la perenne derrota ( $y$, por lo tanto, su negatividad es hipostática), y en cuanto a la utopía, se la convierte en el término inmanente cifrado en las constelaciones.

Pero, al pensar la utopía desde la literatura no hay que olvidar que la pesadilla del atomismo expansivo y heteróclito es, en "Tlion, Uqbar, Orbis Tertius," una de las caras de lo utópico, pero tampoco debe olvidarse que la célebre distinción propuesta por

14 Frances Yates, Giordano Bruno and the Hermetic Tradition, (New York: 1964), p. 360.

15 Max Horkheimer, "La utopia," en Utopla, editada por Arnhelm Neustiss, "Barcelona: Barral Editores, 1971), pp. 91-102. 
Foucault, según la cual las heterotopías inquietan y las utopias consuelan, se dialectiza en el cuento de Borges. ${ }^{16}$ El riguroso orden de lo utópico es en última instancia gratuito, delatando la posibilidad de ser substituido por otro y así hasta el infinito. Pero el trabajo de la historia se manifiesta como límite de las posibilidades: o se regresa o no se regresa del corojal; o se llega a España a bordo del buque La Libre Empresa, o se llega sobre el lomo de una ballena blanca. Entendida, pues, como dato histórico e historiable, la utopía es anuncio de clausura, no del cierre de las posibilidades, sino de la constitución de las reglas del juego. Se busca su instauración para posibilitar el libre juego a partir de la previa configuración de ciertas opciones según los patrones ideales.

Por el contrario, en El mundo alucinante, la confluencia entre utopía y locura se ubicaría en el espacio que he calificado de virtual y refractario, cuyo reflejo alegórico es la tierra de la desolación y de los desperdicios. Todo en ella se niega a ser configurado, buscándose la deformación y la posible ruptura del tú-contigo, pero a través de ello mismo. Foucault ha dicho que "por la locura que la interrumpe, una obra abre un vacio, un tiempo de silencio, una pregunta sin respuesta, y provoca un desgarramiento sin reconciliación, que obliga al mundo a interrogarse... allí donde bay obra, no bay locura; y sin embargo, la locura es contemporánea de la obra, puesto que inaugura el tiempo de su verdad." "17 Foucault no reduce la locura al dato psicológico o a la manifestación irracional. En este sentido, la anchura cósmica que Arenas da a las peripecias de fray Servando (ya de por sí bastante amplias), el mundo alucinante que les hace abarcar, todo ello, representa el acendrado combate del hombre con la zoología fantástica de sus sueños donde, obnibulada y dispersa, su más completa figura transcurre en un tiempo que será preciso recuperar.

Esta concepción del fenómeno locura podria ser enlazada con la vieja peregrinación gnóstica. Al relatar su descenso al mundo, Simón el mago, cuyo nombre latino fue el de Fausto (el favorecido) declara la proliferante ambiguiedad del universo gnóstico:

En cada cielo adquirí una forma distinta según los seres que habitaban en ellos, de modo que pude esconderme de los ángeles que gobiernan, hasta que logré descender hasta Ennoia, a quien también se le nombra Prunikos y Espíritu Santo, y por quien hice a los ángeles y estos al hombre y sus cosas. ${ }^{18}$

Dentro de la gran tradición gnóstica, el conocimiento de las cosas, de las más elevadas a las más bajas, se reúne en la ambigua figura de Sophia-Prunikos, principio femenino de la sabiduría como prurito o comezón, que gobierna las tareas del hombre a ras de tierra, y por el cual éste habrá de reintegrarse a la totalidad al cabo de su larga peregrinación terrenal.

Dicho principio domina la dimensión refractaria y deseante del texto de Arenas. Es el gesto paradójico de la caricia que convida a permanecer en el cuerpo, y de la señal que insta a abandonarlo. Ya he dicho que este aspecto del texto constituye el tercer espacio, el de las posibilidades que puedan. rebasar los encuentros entre el si y el no, pero sin arrivar a la síntesis copulativa. La insistencia con que fray Servando topa con figuras que vendrían a colmar cierta unión, postula la necesidad del término unitivo, que de hecho nunca se da, pues la acción siempre se resuelve a través de las incidencias cómicas de la huida, o se ovilla

16 Ver el prólogo a Las palabras y las cosas, (México: Siglo XXI Editores, 1967), pp. 1-4.

${ }^{17}$ Historia de la locura en la época clásica, (México: FCE, 1967), p. 269.

${ }^{18}$ He creido oportuno trasladar al castellano la versión inglesa de este texto dada por Hans Jonas en su The Gnostic Tradition, (Boston: 1967), p. 108. 
en el ojo del testigo. De hecho, se trata de las estaciones de su martirio, martirio cuya vedada resolución sería erótica: fray Servando y el conocimiento de Borunda, en la cueva excremental donde se le revela la verdadera historia de Guadalupe-Tonatzin; fray Servando y el fraile-rata, con quien se funde y, por tanto, no llega a conocer, pues se trata de él mismo; fray Servando y el párroco americano, el troglodita cuyas proezas litúrgicas con un rebaño de devotas mujeres son atisbadas por el fraile en el interior de una encaracolada parroquia madrileña de escalerillas enredadas y estrechos pasadizos; fray Servando y la priápica lady Orlando; fray Servando y Heredia...

En El siglo de las luces, el mismo principio del conocimiento deseante encarna y se consuma. Sofía es el núcleo de la energía que rompe el tú-contigo, precipitando las cosas. Su frase " "ihay que hacer algo!" ocupa el mismo registro del " $Q Q$ Que suceda! ¿Que suceda siempre algo!" pronunciado por fray Servando. Al igual que el fraile, Sofía encarna el libre juego de la representación y de la alegoría, en cuanto en ella se enlazan la vida y la muerte. Los vínculos eróticos entre ella y, de un lado Victor y del otro Esteban, repiten el tema barroco de la confluencia entre eros y tanatos: como hermana y madre de Esteban, Sofía "conoció las sucesivas formas de [su] cuerpo;" y con Victor ya no se trata solamente de atesorar las figuras pretéritas de la carne fraternal: "Situados fuera del tiempo, acortando o dilatando las horas, los yacentes percibian en valores de permanencia, de eternidad, un abora exteriormente manifiesto en lo que de modo remoto y casual lograban percibir sus sentidos entregados al vasto quehacer de un entendimiento total de sí mismos." 19 La dilatación retórica hace resaltar más aún los anticipos mortuorios de esta yaciente unión. Sin embargo, Sofía no se limita a representar la sublimación doméstica de la sexualidad, ni el ámbito privado de los amantes. Ella no es Amor sino ingreso al Día sin Término, al día de la disolución en "un todo tumultuoso y ensangrentado;" día arcaico, de muertos y no de cadáveres. En él Soffa y Esteban se disuelven: "Nadie supo más de sus huellas ni del paradero de sus carnes." ${ }^{20}$

Regreso ahora a mi punto de partida para contrastar dos miradas: la forense (frente al cadáver, que es la forma diferenciada del individuo reducida a los signos de la muerte) y la devota (sin profesión que la ate a ningún cadáver, y que tal vez prefiera no contemplarlo y pasar del cuerpo a su memoria, o aferrarse al fetiche disecado). Ya se sabe que fray Servando, según la tradición, hubo de hurtarle el cuerpo a su cadáver para entregarlo a la momia, o a cuatro de ellas que se disputarán su último gesto. El fraile ha perdurado para la curiosidad, la devoción o el impulso creador. En el Gran Panótico, su torcida verticalidad permanece suspendida entre el polvo y los signos médicos con que hubiese poblado el espacio de la mirada forense. Por su parte, Sofía y Esteban también se escabuyeron a la exactitud de este destino al fundirse con el cuerpo de la colectividad en rebelión.

Unas palabras de Foucault me sirven para cerrar esta fantasía. Su resumen de la experiencia barroca de la muerte me parece difícil de igualar: "Conocer la vida solo le es dado a ese saber burlón, reductor, y ya infernal que la desea muerta. La mirada que envuelve, acaricia, detalla, anatomiza la carne más individual, y señala sus secretos mordiscos, es esta mirada fija, atenta, un poco dilatada, que desde lo alto de la muerte ha ${ }^{19} \mathrm{El}$ siglo de las huces, p. 267.

$20 \mathrm{El}$ siglo de las luces, p. 297. 
condenado ya la vida." 21 Pero ésta no es la mirada forense, la cual se ajusta a los datos individuales, y sustrae al objeto de su ciencia (el cadáver) del gesto universal y solidario. Este gesto define para Foucault la sensibilidad pre-moderna sobre la muerte. Pues hasta el barroco, la muerte "atraía irrevocablemente a cada uno hacia todos; las danzas de los esqueletos figuraban, a la inversa de la vida, especies de saturnales igualitarias; la muerte, infaliblemente, compensaba la suerte.", 22 Y será esa "sorda vida común" la que, precisamente en los tiempos de la revolución francesa, se borrará de la experiencia. La muerte abandonará su "viejo cielo trágico" para refugiarse " "bajo el signo de la finitud," y de "la Ley, la dura ley del límite," según la cual la individualidad tendrá como destino "tomar siempre una figura," hacerse visible testimonio para la mirada clínica. ${ }^{23}$

Por mi parte, al insistir en las relaciones entre el cuerpo y su desaparición, su diagnóstico final y su posible preservación, a la vez festiva, macabra y ejemplar, he querido trazar algunos de los recorridos imaginarios que El mundo alucinante promueve en su lector. Si algo emerge de los rumbos que he seguido es que la vieja disyuntiva entre lo racional y lo irracional se borra ante una experiencia creadora cuyo principal estatuto consiste en no temerle a los disfraces sino en adoptarlos, porque es en su superficie, siempre equívoca y cambiante, donde el hombre todavía conversa en libertad. 
